\title{
Finishing the Match: A Skill Which Requires Specific Coaching for Female Tennis Players
}

\author{
Federico Di Carlo \\ Atri, 64030 (Te), Italy
}

\begin{abstract}
Tennis psychology has often considered a tennis match divided into three mental phases: beginning, development and finish. The last stage of a match, the finishing one, has always been acknowledged as paramount and a crucial factor to a player's success. The competitive situation of finishing a match can be extremely stressful. Female players have a natural and biologic tendency to live and face this situation differently from male players. The mental association of "finishing" a match and "finishing" an opponent provokes turmoil in the female mindset since she hesitates between her professional due and her natural instinct to preserve life. Male biological, sociological and psychological development adapted him to the symbolic act of eliminating his opponent. The ability to finish off a match is pivotal for a player success and female players should master that ability since it is a paramount competitive advantage. Behaviours can be learnt and modified, so even the finish off a match can be trained and improved.
\end{abstract}

Key words: Performance, killer instinct, competitive advantage, neuro-science, coaching.

\section{Introduction}

Tennis psychology has often considered a tennis match divided into three mental phases: beginning, development and finish. The last stage of a match, the finishing one, has always been acknowledged as paramount and a crucial factor to a player success. The mental ability to finish off a match is very often referred to as "killer instinct". Several researchers studied the issue from several points of view: concentration [1-3], determination [4], suggestions on how to practice it [5] on court but they never investigated the sociologic, biologic and neuro scientific aspect of the issue.

The word "killer instinct" itself suggests the image of a tennis match as a struggle for survival [6]. Even if we considered the points of a match equally important, at the end of the match, one of the two players will lose and be eliminated from the tournament. So both tennis players are in the position to "finish" the opponent, survive in the contest and stay alive in the tournament.

The act of "terminating" the opponent has a deep and

Corresponding author: Federico Di Carlo, B.A., research field: languages and humanistic sciences. important impact on the player mental state and above all on the female players.

\section{Material and Methods}

Biological, sociological and neuro scientific find outs suggest that the symbolic act of "eliminating an opponent" is harder for a female player than a male one. Human brain and psychology developed in history according to the role that both genders had in the evolution of the species. Human brain was not made and did not develop to play tennis.

\subsection{The Biologic Aspect}

Human female place in the biologic chain is to give birth to babies and protect her beloved from dangers and predators. She can be ferocious and ready to die for defending her babies, to preserve life. The flip of the coin is that she becomes extremely vulnerable when asked to be the aggressor, to attack and to take life away from other human beings in offensive way. When she is required to take life away, she struggles with her natural instinct to preserve life. This internal fight provokes intense doubts and lots of troubles on a tennis court during the phase of the match finishing off. On 


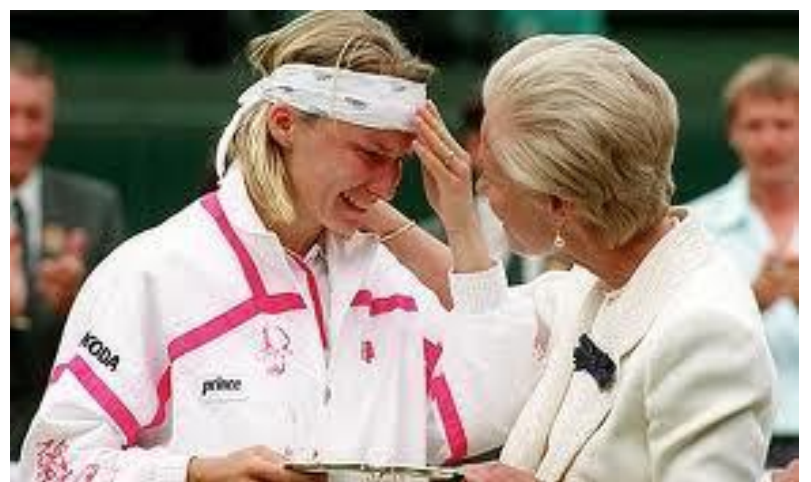

Fig. 1 The Czech player Jana Novotna in tears after losing the 1993 Wimbledon final. She squandered a lead 6-7 6-1 4-1 40-30. Steffi Graf won the match 7-6 1-6 6-4.

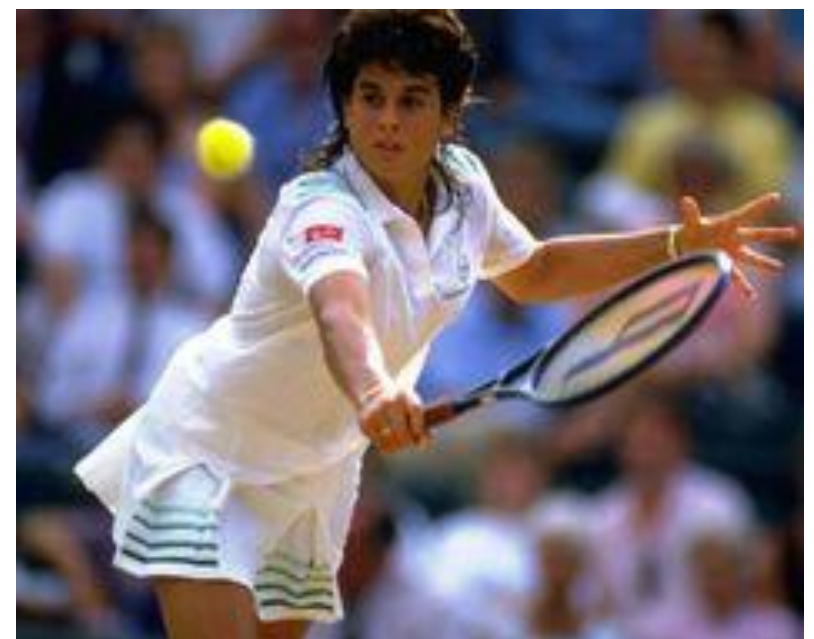

Fig. 2 The Argentinian Gabriela Sabatini in the 1993 French Open quarter final squandered a lead of 6-1 5-1. The American Mary Joe Fernandez won the match 1-6 7-5 10-8.

the last stages of a match, a female may hesitate between her professional due and her natural instinct to preserve life. She instinctively feels mercy for her opponent. On these situations, female players (though it happens for male players too) very often rely on opponent mistakes as to avoid the responsibility for the opponent loss. And when both female players are in the same mental state, sometimes matches have a sort of tragic/comic epilogue with both fearsome to win the match (Fig. 1). When the emotive states take the upper hand in the player mental state, match becomes highly unpredictable (Fig. 2).

\subsection{The Sociologic Aspect}

Until twentieth century achievements in personal, working and social rights, the social development of women was different than male one. Woman place in society had been perceived as the "angel of the hearth", that is the one in charge to look after the family. That is the sense of the "matriarchal society". She was not expected to have a career in sport and business. That was male role. Most times, women experience winning through the mis-concept of historical social heritage. In her mind, victory is not what is expected from her role and may be interpreted as a social rejection rather than a social reward.

\subsection{The Neuroscientific Aspect}

Neuroscience proved that the emotional brain, the old mammalian, the one who responds to the fight or flight mechanism, is bigger in female than in male [7]. Since female needs to care not only about herself but about babies too, her response to potential danger is bigger than in males. Female emotional brain developed accordingly. To my knowledge today, there is no neuroscientific evidence which describes and compares male/female neuro patterns and biochemistry difference on situations where killer instinct is required.

\subsection{Gender Differences}

Male players' instinctive behavior in the match finishing off is somehow different. That means that male do not care for other human beings life? Of course male do and male players sometimes have trouble with the finishing of the match, too. Tennis history has plenty of male chocking cases. However, from a biologic and sociologic point of view, male developed differently and have an advantage over female on the issue. The social and functional role of male in biologic chain is that of hunter. Male was the one supposed to provide food for the family which means killing other forms of life for survival. Basically male biological and psychological development is mors tua, vita mea, your death is my life. A male player is somehow used to the symbolic act of eliminating his opponent. Somehow, 
male players rationalized that terminating the opponent stay in the tournament is not nice but it is part of the job in order to survive. Male player may not like to "eliminate" opponent but does not have any regret and the act of doing it provokes less or any internal turmoil. A dirty job, but someone must do it. And male was the one supposed to do it and he adapted to it in time. The perspective of finishing off a match for a male player is part of a work ethics and provokes less internal emotional fight.

\section{Tennis Implications}

Though the finishing off issue maybe more frequent on the International Tennis Federation tournaments and lower level tennis, sometimes it happens even at higher levels too ${ }^{1}$.

Of course, the more players are close and have strong relationships, the bigger the feeling of guilt for "finishing" the opponent. This is maybe one of the reasons for lack of comradeship between female players at the top of the game, which is more frequent than in male. Many female players may complain about it, but avoiding strong personal relationships with other players may be seen as an essential part of being a professional female tennis player. The ability to finish off a match is pivotal for a player success and female players should master that ability since it is a big competitive advantage.

Usually during the early stages of a tennis player activity, above all in ITF tournaments, young tennis players may find themselves alone in God forgotten places around the world and need social and human contact. And that is how players make friendship and start personal relationships. However, this has a worsening effect on the female ability to finish the match on the court.

\footnotetext{
1 The 2012 US Open edition scheduled at quarter finals Sara Errani against Roberta Vinci. They are very close friends in everyday life, travel very often together in the same tournaments, used to play doubles together and play in the Federation cup for the same team. Their match was considered by many commentators as one of the less competitive and less agonistic Grand slam quarter final ever.
}

Besides many female players report that colleagues who showed friendship on the early stages, let it down no sooner they were beaten on the court. This shows that at intuitive or at deep level, some players know that personal relationships may have important impact on performance and they try to take advantage from it.

In male tennis, comradeship is more frequent even at higher levels and usually does not have any influence on players killer instinct. Male players set apart aspects of the business and aspects of social life more easily [8, 9]. For female players, it is tougher.

\section{Cognitive Training Program Principles}

As in the case of all mental abilities, the ability to finish matches can be trained and improved.

In order to enhance a female player killer instinct from a mental, cognitive point of view, we recommend training the skill off the court keeping the above key points in mind.

The devil you know is better the devil you don't. Cognitive training starts with consciousness. Explain the biologic factor behind the "killer instinct". Athletes may have difficulty in understanding the reason, for example, male and females need different approach towards the issue. Make sure they know what they are working for. It will speed learning and practicing processes up.

Non Satis Scire. To know is not enough. Knowing the ability does not mean having the ability to execute it. Point out that finishing matches off is a mental skill which is paramount to achieving success. Athletes should perceive that finishing matches should be a training goal. A goal which needs the implementation of a training program and deserves the same work and commitment reserved to technical and athletic practicing.

You bring in sport what you are in life. Clarify that working on match finish means working on the person too. Any change which is brought to a personal level implies initial discomfort. Humans are "being of 
habits". Being exposed to unfamiliar and unknown situations (horror vacui) means getting out of personal psychological comfort zone. Refusal is the first natural reaction to change. Improvement usually goes by two steps in front and one backwards. Make them understand that tennis is their job and there is no identification whatsoever between the job results and the person. Tennis is your sport, what you do, and not what you are. Changing requires motivation, plenty of work and resilience. Make sure athletes are ready, willing and assume responsibility about it.

Nothing happens for real if it doesn't take place in the mind first. Train the player mind with visualization. Check, identify and explore in the player mind worse-case scenarios. What if they beat the opponent? Will they lose friendship? Is it maybe "faked" or "interested" friendship? Create images of on court real situations, rehearse desired self talk, emotional management and outcome. Imagine difficulties and solutions. Enhance visualization with bright images, clear sounds and positive feelings.

A professional sport is not a part time hobby. It is extremely important that female players have always in mind goals, "work ethic" and professional mentality and attitudes. For female athletes, avoiding friendship with other tennis players maybe one of the sacrifices and renounces required to achieve their best potential. It may be difficult understanding the reasons for isolating or being unsociable to fellow tennis players. As a coach, try to enhance the player social activity outside the tennis world and avoid personal relationships with colleagues as much as possible.

\section{Conclusions}

The ability to finish off a match is pivotal for a player success. As in the case of most skills, the finish off a match can be trained and improved. Male and female experience the finishing of the match from a different perspective which requires special coaching for female athletes. Female players should master the ability of finishing a match off since it is a paramount gender competitive advantage.

Many researchers provided valuable clues on how train and improve the finish off a match on a practical level. However, poor or no attention has been given to the cognitive aspects of the issue.

New approaches in neurosciences with brain scanning technologies open new frontiers and promise new insights on this intriguing subject.

\section{References}

[1] Weinberg, R. 2013. Winning the Mental Game. Oxford, Ohio: Zinman Inc.

[2] Gallwey, T. 2008. The Inner Game of Tennis. NY: Random House.

[3] Spang, P. 1988. Zennis. NY: The Berkley Publishing Group.

[4] Gilbert, B., and Jamison, S. 1994. Winning Ugly. NY: Simon \& Schuster.

[5] Fox, A. 2010. Winning the Mental Match. NE, US: Morris Publishing, Kearney.

[6] Murray, J. 1996. Developing the Killer Instinct. Accessed November, 26, 2015. http://www.tennisserver.com/mental-equipment/me_12_9 6.html

[7] Di Carlo, F. 2012. "Tennis Brain”, original title Il Cervello Tennistico. Vasto, \&mybooks.

[8] Connors, J. 2013. The Outsider: A Memoir. NY: HarperCollins Publishers.

[9] McEnroe, J., and Kaplan, J. 2002. You Cannot Be Serious. NY: Putnams Sons Publishers. 